\title{
O setor de telefonia móvel do Brasil após o SMP: as estratégias das operadoras e a convergência fixa-móvel*
}

\author{
Rogério H. Quintella** \\ Márcio Andrade Costa***
}

SumáRIo: 1. Introdução; 2. Procedimentos metodológicos; 3. Uma breve revisão da literatura; 4. As consequências da regulação do SMP para a estrutura do mercado; 5. Estratégias competitivas das operadoras pós-SMP; 6. Os mapas estratégicos do setor, após o SMP; 7. Conclusões; 8. Considerações finais.

Summary: 1. Introduction; 2. Methodological procedures; 3. A brief literature review; 4. The consequences of the PMS regulation for the market structure; 5. Competitive strategies for post-PMS operators; 6. The strategic maps of the sector after PMS; 7. Conclusion; 8. Final remarks.

Palavras-chave: regulação do SMP; estratégia competitiva.

KEY Words: PMS regulation; competitive strategy.

Este artigo analisa como a regulação do Serviço Móvel Pessoal (SMP), implementada pela Anatel em 2001, alterou a estrutura do mercado e as estratégias das operadoras do setor de telefonia móvel no Brasil, entre 2002 e 2007. Foi realizada uma pesquisa qualitativa e um estudo de caso múltiplo acerca das maiores operadoras do setor: Vivo, Tim, Claro e Oi. Diante da análise setorial e da influência de fatores externos sobre a estrutura do mercado, adotou-se o referencial teórico clássico de estratégia

\footnotetext{
* Artigo recebido em mar. e aceito em nov. 2008.

** Doutor em gestão estratégica pela University of Brighton. Professor titular da Universidade Federal da Bahia (UFBA), autor de The strategic management of technology, editor-geral dos periódicos da Anpad. Endereço: Avenida Reitor Miguel Calmon, s/n - CEP 40110-903, Salvador, BA, Brasil. E-mail: rhquintella@gmail.com.

*** Graduado em ciência da computação pela Universidade Federal de Sergipe com especialização em Telecom pelo Ibmec-MG, mestre em administração pela Escola de Administração da Universidade Federal da Bahia (Nacit/NPGA). Professor de graduação e pós-graduação nas áreas de ICT e gestão estratégia de serviços. Endereço: Rua Joventina Alves, 653 — CEP 49020-330, Aracaju, SE, Brasil. E-mail: marcioandradecosta@yahoo.com.br.
} 
competitiva a fim de se entender as estratégias das operadoras. Adotou-se também um referencial mais específico do setor de telecomunicações, com destaque para trabalhos que discutem a convergência entre as telefonias fixa e móvel. Entre as conclusões do trabalho estão os efeitos de caráter deliberado das mudanças na regulação sobre as estratégias empresariais do setor, entre elas a adoção generalizada de estratégias de custo até o lançamento de serviços inovadores no mercado nacional, caracterizados pela integração entre as operadoras de telefonias fixa e móvel, promovendo estratégias de diferenciação, claramente representadas pela formação de dois grupos estratégicos: um com serviços convergentes do tipo bundle e relações de quase integração vertical entre operadoras fixas e móveis e outro com serviços convergentes entre operações de telefonia fixa e móvel verticalmente integradas.

The mobile telephony sector in Brazil after PMS: operators' strategies and landline-mobile convergence

This article analyzes how PMS (Personal Mobile Service) regulation made by Anatel in Brazil in 2001 changed the market structure and the operators' strategies for the telephony sector between 2002 and 2007. It was carried out a quantitative research and a multiple case study about the main operators in Brazil: Vivo, Tim, Claro and Oi. According to this sector analysis and the influence of external factor as regards the market structure, the classic theoretical reference of competitive strategy was used to better understand the operators' strategies. It was also used a more specific reference for the telecommunications sector featuring the works related to the convergence between the landline and mobile telephony. Within the conclusions of this paper, there are the effects related to cost strategy until the rollout of innovative service on a marketwide basis. They are deemed by the integration between the operators of landline and mobile telephony by promoting strategies of differentiation clearly presented by the formation of two strategic groups: the former related to convergent services bundle type and relations of quasi-vertical integration between the landline and mobile operators and the latter related to convergent services between vertically integration landline and mobile operators.

\section{Introdução}

O setor de telefonia móvel no Brasil passou por profundas reestruturações desde o final da década de 1990, quando da sua privatização. Seguindo uma tendência internacional, observada em países como EUA, Inglaterra, França, Japão, Alemanha e também em países da América Latina, como México, Chile, Argentina, Peru e Bolívia, o processo de privatização da telefonia móvel no Brasil, iniciado em 1995, estendeu-se até 1998. Compreendeu, entre outros fatores, o fim do monopólio estatal, a privatização das empresas de telefonia e a aprovação da Lei Geral de Telecomunicações, que estabelecia as condições legais de operação 
do setor e a criação de uma agência reguladora, a Agência Nacional de Telecomunicações (Anatel). As mudanças realizadas pelo governo federal no aparato regulatório, que rege a prestação dos serviços de comunicação no país (Pires, 1999; Novaes, 2000; Neves, 2002), modificaram radicalmente o contexto institucional vigente há 20 anos. Como resultado, o Brasil encerrou o ano de 2007 com um total de 121 milhões de celulares em uso (Anatel, 2008).

O mercado de telefonia móvel resultante desse processo tinha características distintas do monopólio estatal anterior a esse período: nove empresas privadas conformavam a denominada banda B da telefonia móvel celular competindo com oito operadoras estatais, posteriormente privatizadas, denominadas empresas banda A. O mercado tinha seu capital controlado por 20 grupos distribuídos em 10 regiões geográficas do território nacional (Anatel, 2007d, 2007e). As normas que regulavam o setor a partir daquele ano conformavam o que a Anatel (2006a) denominou Serviço Móvel Celular (SMC). Em 2001, essa mesma agência realizou a venda de novas licenças para a exploração da telefonia móvel no país, introduzindo as chamadas bandas C, D e E, por meio de novas licitações e de um novo conjunto de normas, conformando um novo aparato, agora denominado Serviço Móvel Pessoal (SMP). Desde então, alguns importantes fatos públicos puderam ser observados no setor como: a introdução da tecnologia GSM (global system mobile communications); o aumento do número de operadoras móveis, competindo em uma mesma região geográfica; novos planos de serviços que incluíam, além das chamadas para celular, chamadas de longa distância nacional ou serviços de telefonia fixa, móvel e acesso à internet em um único pacote; e a participação de capital dos grupos controladores das operadoras móveis nas operadoras da telefonia fixa e vice-versa. Diante da percepção de tantas e tão grandes mudanças, este artigo tenta responder à seguinte questão: como a regulação do SMP influenciou as operadoras de telefonia móvel a adotar suas respectivas estratégias para o mercado brasileiro no período de 2002 a 2007 ?

\section{Procedimentos metodológicos}

Este artigo está dividido em quatro partes que almejam, respectivamente, identificar as alterações regulatórias promovidas pelo SMP; ${ }^{1}$ caracterizar a es-

\footnotetext{
${ }^{1}$ Uma vez detalhado o processo de licitação do SMP, foi realizada uma pesquisa documental junto à biblioteca da agência, catalogando-se 34 resoluções que se referem às normas e regulamentos 
trutura do mercado decorrente de tais alterações; identificar as estratégias implementadas pelas operadoras diante dessa estrutura; e analisar seus efeitos sobre a competição no setor. A estratégia de pesquisa utilizada foi a do estudo de caso múltiplo (Yin, 2003), compreendendo as quatro maiores operadoras do mercado no Brasil. A metodologia foi primordialmente qualitativa (Lakatos e Marconi, 1991; Richardson et al., 1999; Martins, 2006), e permitiu captar comportamentos acerca do fenômeno observado que possivelmente não seriam percebidos de outra forma. Foram utilizadas pesquisa documental, entrevistas, análise de conteúdos e observações como técnicas de coleta (Patton, 2002; Vergara, 2005), de forma a permitir a triangulação das evidências observadas (Yin, 2003; Vergara, 2005), como está no quadro 1.

\section{Quadro 1 \\ Representação das etapas da pesquisa, os métodos de coleta e fontes de dados}

\begin{tabular}{|lll|}
\hline $\begin{array}{l}\text { Fases da análise } \\
\text { dos dados }\end{array}$ & Método de coleta dos dados & Fonte dos dados \\
\hline SMP (aspecto regulatório) & Documental & Leis e decretos federais \\
& Observação & Editais da Anatel \\
& Entrevista & Congresso ITU-Telecom Americas 2005 \\
& Análise de conteúdo & Análises setoriais - BNDES \\
& & Entrevista com o gerente regional da \\
& Anatel \\
Mercado (estrutura) & Documental & Sites institucionais das operadoras \\
& Observação & Relatórios setoriais - Anatel \\
& Entrevista & Revistas e periódicos - especializados \\
& Análise de conteúdo & Entrevista com o gerente regional da \\
& & Anatel \\
\hline
\end{tabular}

mais pertinentes às alterações regulatórias do SMP ante a regulação anterior até o limite cronológico da pesquisa. A utilização de tais resoluções publicadas pela Anatel, como fonte documental de pesquisa, em detrimento a outros tipos de documentos publicados pela mesma agência, teve como critério o que consta no art. 1ํ do Decreto nํㅜ 3.896/2001 da Presidência da República: "Os serviços de telecomunicações, qualquer que seja o regime jurídico ou o interesse, regem-se exclusivamente pelos regulamentos e pelas normas editadas pela Agência Nacional de Telecomunicações - Anatel, não se lhes aplicando a regulamentação anteriormente vigente (...)". Nesse sentido, foram selecionadas as resoluções que tratam especificamente sobre o serviço móvel pessoal, publicadas até maio de 2007. 


\begin{tabular}{|lll|}
\hline $\begin{array}{l}\text { Fases da análise } \\
\text { dos dados }\end{array}$ & Método de coleta dos dados & Fonte dos dados \\
\hline $\begin{array}{l}\text { Comportamento } \\
\text { (estratégia) das } \\
\text { operadoras }\end{array}$ & $\begin{array}{l}\text { Documental } \\
\text { Observação } \\
\text { Entrevista } \\
\text { Análise de conteúdo }\end{array}$ & $\begin{array}{l}\text { Sites institucionais das operadoras } \\
\text { Mídia } \\
\text { Mercado (competição) } \\
\text { das operadoras }\end{array}$ \\
& $\begin{array}{l}\text { Documental } \\
\text { Observação } \\
\text { Entrevista } \\
\text { Análise de conteúdo }\end{array}$ & $\begin{array}{l}\text { Relatórios setoriais - Anatel } \\
\text { Revistas e periódicos - especializados nacionais }\end{array}$ \\
& Entrevista com o gerente regional da \\
& Anatel \\
\hline
\end{tabular}

Tendo em vista a realização de uma análise setorial, a pesquisa para este artigo envolveu entrevistas com os executivos de todas as operadoras em questão - diretores nacionais das áreas de marketing ou vendas. Para realizar a análise dessas entrevistas foi utilizada a análise de conteúdo (Vergara, 2005:15) com procedimento qualitativo, buscando identificar elementos representativos aos pressupostos da pesquisa em pauta e "permitindo a construção interativa de uma explicação" (Laville e Dionne, 1999, citados por Vergara, 2005).

\section{Uma breve revisão da literatura}

\section{Telefonia móvel}

A literatura aborda o setor das telecomunicações de modo abrangente e com diferentes propósitos. É possível identificar uma visão histórica das telecomunicações no Brasil (Cavalcante, 1999; Novaes, 2000; BNDES, 2001; Dias, 2002), que retrata a evolução cronológica do setor, associando eventos a períodos específicos da história no país; trabalhos sobre estratégia em telecomunicações que tratam, em sua maioria, da perspectiva das empresas de telefonia fixa ou móvel ante a seus clientes e serviços (Santa Rita e Sbragia, 2004; Guilhoto e Rubal, 2004); análises das características dessa indústria no país (Ribeiro Filho e Correia, 1999; Sbragia et al., 2004); análises das características do setor nos países de economia mais desenvolvida (Armstrong, 1997; Gaffard e Krafft, 2000; Fransman, 2001a, 2001b); trabalhos sobre as telecomunicações no país restritos ao período da privatização (Pires, 1999; Freitas, 2000; BNDES, 2001; Salgado e Mota, 2005); e análises comparativas entre as tecnologias (Bloch-Morange e Fontela, 2003; Pereira e Guedes, 2004). Tais publicações, no entanto, não abordam características atuais de prestação do serviço, como 
a integração de serviços (Passmore, 2005; Curwen, 2006; Buckley, 2007) de telefonia fixa e móvel disponibilizados por uma mesma operadora.

\section{Referencial teórico}

O referencial teórico utilizado foi o da análise estrutural da indústria, por permitir uma análise dos fatores determinantes das estratégias, "determinando as regras competitivas do jogo, assim como das estratégias potencialmente disponíveis para a empresa" (Porter, 1980:22). A visão de Porter (1980), sobre as forças competitivas que atuam sobre uma indústria, supõe a existência de estratégias competitivas mais adequadas para cada tipo de mercado como demonstram os trabalhos empíricos (Schmalensee, 1985; Miller, 1988; Venkatraman e Prescott, 1990a, 1990b) que relacionam o desempenho das firmas com as características estruturais da indústria a que pertencem. Tal proposta é coerente com a pesquisa que serviu de base para este artigo, já que este visa analisar a estrutura do mercado e as estratégias implementadas pelas operadoras móveis em decorrência de tal estrutura, tomando-se como ponto de partida as alterações no contexto regulatório do setor. A literatura fornece outro rico referencial que busca, nos recursos internos das firmas (resource-based view - RBV), suas fontes de vantagens competitivas (Wernerfelt, 1984; Barney, 1986, 1991; Peteraf, 1993). Nessa abordagem, "os recursos da firma em um dado período podem ser definidos como ativos a ela atrelados de maneira semipermanente" (Wernerfelt, 1984:172). A vantagem competitiva aqui definida (Peteraf e Barney, 2003) é, porém, ainda semelhante àquela de Porter. Nessa visão o mercado é o locus da oferta dos produtos originados dos recursos internos das firmas (Teece, Pisano e Shuen, 1997; Foss e Knudsen, 2003). Sobre esse referencial algumas análises empíricas comprovam a correlação entre fatores internos da firma e o retorno médio da indústria (Rumelt, 1991; Hansen e Wernerfelt, 1989; Rouse e Daellenbach, 1999), ainda que necessitem ser expandidas (Barney, 1991). Apesar de seus progressos, a RBV não pode ser considerada uma abordagem que substitua os modelos tradicionais da análise do mercado ou mesmo ser usada para análise entre indústrias (Peteraf e Barney, 2003), mas sim como uma visão complementar no nível da firma (Foss, 1996) inserindo outra concepção da estratégia.

Retomando a abordagem de Porter, contida pela escola do posicionamento (Mintzberg, 1987; Mintzberg, Ahlstrand e Lampel, 2000), pode-se dizer que sua visão intraindústria percebe diferentes posicionamentos da firma em seu interior, possibilitando, quando da análise de um conjunto, a observa- 
ção de grupos estratégicos. Segundo McGee e Thomas (1986:10), "uma firma dentro de um grupo estratégico toma decisões estratégicas que não podem ser imitadas imediatamente por firmas de fora de seu grupo estratégico sem que incorra em vultosos custos", como pode ser visto em diversas pesquisas (Dess e Davis, 1984; Hatten e Hatten, 1987; Cool e Schendel, 1988; Aaker, 1989; Mascarenhas e Aaker, 1989; Dranove, Peteraf e Shanley, 1998) que buscaram identificar as características que diferenciam as firmas de um grupo estratégico. Assim, entende-se que há importantes complementaridades entre as estratégias genéricas e os grupos estratégicos aqui referenciados.

\section{O arcabouço regulatório do SMP}

O Serviço Móvel Pessoal (SMP) constituiu o arcabouço regulatório implementado pela Anatel em 2001 em substituição ao Serviço Móvel Celular (SMC) - conjunto de normas que regulava o setor de telefonia móvel no Brasil desde a sua privatização. Em 21 de setembro de 2000, as primeiras diretrizes sobre o SMP foram aprovadas pela Anatel, e seguidas pelo Edital de Licitação do SMP, aprovado pelo Ato no 13.140, de 24 de novembro de 2000. Esse edital previa a licitação de três regiões geográficas - I, II e III - equivalentes às regiões de exploração da telefonia fixa, contendo três faixas de frequências de operação denominadas bandas $C, D$ e E, totalizando nove licenças de exploração do serviço móvel no país. A licitação decorrente do SMP teve início no mês de janeiro de 2001, porém as primeiras licenças só foram efetivamente vendidas no mês subsequente, estendendo-se até novembro de 2002, quando foram vendidas as últimas licenças das bandas D e E. Importante ressaltar que não houve interessados na aquisição das licenças da banda C. ${ }^{2}$

A análise das 34 resoluções que se referem às normas e regulamentos mais pertinentes às alterações regulatórias do SMP revela que as alterações que emergem desse conjunto de normas podem ser agrupadas em três tipos de documentos: aqueles que têm por objeto o Regulamento do SMP (Resoluções nos $245 / 2000$ e 316/2002); os que têm por objeto o Plano Geral de Autoriza-

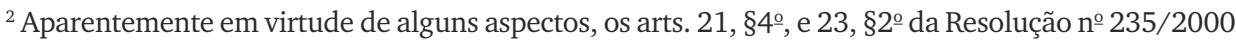
da Anatel, que determinavam, respectivamente, que as operadoras vencedoras da Banda C antecipassem suas operações às operações das bandas D e E em até seis meses após a assinatura do termo de autorização, porém, não permitiam que a operadora licitante fosse controladora, controlada ou coligada de operadora do Serviço de Telefonia Fixo Comutado (STFC).
} 
ções (Resoluções nos 248/2000, 268/2001, 321/2002 e 466/2007); e o Plano Geral de Metas de Qualidade. ${ }^{3}$ No que tange ao regulamento e ao Plano Geral de Autorizações do SMP as principais alterações identificadas foram:

v o tipo de formalização da licença para a exploração do serviço que alterou a relação contratual entre as operadoras e a Anatel, constituindo uma autorização para a exploração de serviço público, extinguindo a "reversibilidade dos bens das operadoras móveis" (possível no contexto regulatório anterior por uma relação contratual de concessão ou autorização); ${ }^{4}$

v as novas faixas de frequência de transmissão do sinal de rádio pelas operadoras, implicando introdução da tecnologia GSM no mercado. Deve-se ressaltar que a função da Anatel não é determinar a tecnologia a ser adotada pelas operadoras móveis, mas sim, como órgão que regula o espectro de frequência dos sinais de transmissão das comunicações móveis, determinar a faixa de frequência de operação dos serviços. No entanto, tal escolha termina por determinar as opções tecnológicas das operadoras móveis. ${ }^{5}$ Não se pode deixar de observar que a opção tecnológica de uma rede pode ser decisiva no critério de evolução da mesma, fazendo com que esta se transforme em sunk cost ou ainda que (devido à característica de quase verticalização dessa indústria) obtenham-se ganhos de escala e melhores condições de negociação com os fornecedores (Porter, 1980);

$\checkmark$ a participação de grupos que já controlavam operadoras de telefonia fixa ou móvel no processo de licitação do serviço móvel. Entre as quatro

\footnotetext{
${ }^{3} \mathrm{O}$ qual contém alterações perante o SMC no que se refere aos indicadores de qualidade para a prestação do serviço móvel. Tendo em vista o objetivo deste artigo, os indicadores de qualidade foram desconsiderados.

${ }^{4}$ Diante da regulação anterior, a concessão permitia que todo e qualquer ativo de uma operadora se tornasse reversível ao governo, quando este entendesse a necessidade de continuação do serviço em favor da sociedade. A partir do SMP, os bens das operadoras móveis tornam-se irreversíveis. ${ }^{5}$ Como pode ser identificado em dois momentos da história das telecomunicações no país: durante a privatização do setor ou na licitação do SMP. No primeiro momento, a Anatel determinou os espectros de frequência que suportavam a operação das tecnologias TDMA e CDMA e cada operadora móvel fez sua opção por um padrão entre eles, resultando na tecnologia TDMA pela maioria das operadoras celulares estatais, à exceção da Telesp Celular e da Telerj Celular. Entre as operadoras privatizadas, a Global Telecom foi a única que optou pela tecnologia CDMA, enquanto as demais operadoras fizeram escolha pelo padrão TDMA, conforme relata Dias (2002); em um segundo momento, durante o processo de licitação do SMP, a Anatel determinou as faixas de frequência de $1.800 \mathrm{MHz}$ a serem utilizadas pelas novas operadoras, determinando o padrão GSM europeu a ser adotado, já que esse era o único padrão que operava na frequência determinada. Tal decisão disponibilizou a frequência de $1.900 \mathrm{MHz}$ para a terceira geração da tecnologia móvel (3G), seguindo o que sugeria a União Internacional de Telecomunicações (Dias, 2002).
} 
operadoras aqui analisadas, os controladores da Vivo e da Oi já exploravam o serviço de telefonia fixa, controlando as operadoras Telefônica e a antiga Telemar. O SMP também permitiu que grupos que já exploravam a telefonia móvel nas bandas A e B adquirissem novas licenças no processo de licitação das bandas $\mathrm{C}$, D e E, complementando sua área de atuação no país, como ocorreu com a Tim que criou uma operação em nível nacional;

v a redefinição das áreas geográficas de exploração do serviço no território nacional, não mais em dez regiões como definido anteriormente no SMC, mas em três regiões - regiões I, II e III —, distribuídas similarmente às mesmas regiões I, II e III da telefonia fixa, conforme consta no art. $4^{\circ}$ do Decreto no 2.534, de 2 de abril de 1998, que aprova o "Plano Geral de Outorgas" do Serviço de Telefonia Fixo Comutado. A relevância desse fato está na coincidência entre as áreas de operação da telefonia fixa com as áreas de operação da telefonia móvel, e tanto a Vivo quanto a Oi são exemplos de operadoras que ofertam seus serviços móveis nas mesmas regiões que as empresas de telefonia fixa, pertencentes aos seus grupos controladores — Telefônica, Portugal Telecom e antiga Telemar —, disponibilizavam o serviço telefônico fixo comutado;

v a possibilidade de seleção do Código de Prestadora (CSP) que provocou impacto tanto para os usuários do serviço móvel celular, quanto para as operadoras que lhes prestavam tal serviço. Com a introdução do CSP, o cliente pode, a partir de então, selecionar qual a operadora de longa distância de sua preferência. ${ }^{6}$ Ressalte-se aqui que, no contexto regulatório anterior, a operadora de longa distância era pré-determinada pela prestadora do serviço móvel celular;

v o direito a uma licença de exploração do serviço de telefonia fixa de longa distância em todo o território brasileiro. ${ }^{7}$ Entre as quatro operadoras

\footnotetext{
${ }^{6}$ As operadoras móveis devem possibilitar a escolha da operadora de longa distância pelo cliente final, e tal escolha será por opções de preço ou qualidade do serviço, segundo a percepção do cliente.

${ }^{7}$ Esse direito estendeu-se às empresas que adquiriram uma licença para exploração do Serviço Móvel Pessoal, decorrendo, daí, que uma operadora vencendo a licitação relativa a qualquer área do SMP automaticamente recebe o direito de prestadora dos serviços de DDD e DDI em nível nacional. Diante da possibilidade de escolha do CSP pelo cliente, mencionado anteriormente, esse direito de exploração poderia ser utilizado pela operadora móvel do SMP para estender seu escopo de serviços em direção às chamadas de longa distância nacional ou internacional, adentrando no mercado da telefonia fixa.
} 
aqui analisadas, a Tim e a Claro criaram suas operadoras de longa distância com os códigos 41 e $36,{ }^{8}$ respectivamente. Segundo a entrevista com a Anatel, o objetivo da agência, com tal alteração, era estimular a concorrência na telefonia fixa por meio das operadoras móveis, quando elas disponibilizassem a oferta de serviços de longa distância.

\section{As consequências da regulação do SMP para a estrutura do mercado}

As principais alterações promovidas pelo SMP devem ser entendidas como mudanças na política governamental do setor, como denomina Porter (1980:162). Essas mudanças ocasionam um processo evolutivo na indústria, já que as fontes das forças competitivas que sobre ela atuam foram afetadas, como será discutido adiante.

Como apresentado, o SMP permitiu, por meio das Resoluções no $248 / 2000$ e no $321 / 2002$, em seus arts. 16 e 17, a participação de grupos que controlavam operadoras de telefonia fixa ou móvel em seu processo de licitação, engendrando a redução das barreiras de entrada no setor para as operadoras de telefonia fixa ou as barreiras de mobilidade (Porter, 1980; McGee e Thomas, 1986) para as operadoras de telefonia móvel que já atuavam nas bandas A e B. Analisando a estrutura de capital das operadoras em questão observa-se que o grupo da Oi já controlava uma operadora de telefonia fixa, a Telemar. A $\operatorname{Tim}^{9}$ e a Vivo, por sua vez, situam-se entre as operadoras cujos grupos controlavam algumas operadoras de telefonia fixa e móvel, concomitantemente. A Claro, por sua vez, é a única operadora cujo grupo não controlava, ainda, operadoras de telefonia fixa ou móvel. A intensificação da concorrência no setor pode ser observada a partir do SMP, tendo em vista a entrada de novas operadoras, compondo as bandas D e E, pois, a partir desse período, 92,5\% dos 91,8 milhões de assinantes do SMP (Teleco, 2006) eram assistidos por mais de três operadoras de telefonia móvel ante as duas opções (bandas A e B) iniciais. No entanto, apesar de intensificar a concorrência em nível regional, o setor de telefonia móvel apresentou movimentos de consolidação das operadoras em nível nacional,

\footnotetext{
${ }^{8}$ O grupo controlador da operadora Claro adquiriu a Embratel em 2005, operadora que já prestava o serviço de longa distância no mercado, obrigando o grupo a abandonar a oferta do código 36 da Claro em favor do código 21 da Embratel, conforme exposto na entrevista com seu diretor.

${ }^{9}$ A Tim detinha participação nas ações da Brasil Telecom até o SMP.
} 
uma vez que grupos controladores de operadoras das bandas A e B adquiriram licenças do SMP, controlando operadoras das bandas D e E, a exemplo da Tim ou, em sentido inverso, a exemplo da Claro (por meio da Telecom Americas) que adquiriu licenças das bandas D e E, criando e controlando sua própria operadora nos estados do Paraná, Santa Catarina, Bahia, Sergipe e interior de São Paulo, adquirindo, em seguida, as operadoras das bandas A e B: BCP, ATL, BSE, Telet, Tess e Americel. A Vivo migrou sua licença para o SMP, adquirindo, em seguida, uma operadora da banda A, a operadora TCO. A Oi, por sua vez, não apresentou movimentos de aquisição de operadoras. O fato de os grupos controladores dessas operadoras possuírem já algum controle sobre operadoras de telefonia fixa justifica outra evolução estrutural no setor — os níveis de integração vertical entre operadoras de telefonia fixa e móvel. É possível perceber que quatro alterações promovidas pelo SMP possivelmente favoreceriam o estabelecimento de maiores níveis de integração vertical entre as operadoras de telefonia móvel e as operadoras de telefonia fixa: a primeira diz respeito aos participantes do SMP, permitindo que empresas concessionárias (operadoras) da telefonia fixa concorressem a licenças móveis, como controladora, controlada ou coligada; a segunda refere-se às áreas geográficas licitadas pelo SMP, que coincidem com as áreas de atuação das empresas concessionárias da telefonia fixa; a terceira alteração é a que estabelece o Código de Seleção de Prestadora (CSP), que permite ao cliente selecionar a operadora de longa distância nacional ou internacional de sua preferência para a realização de chamadas desse tipo; a quarta atribui o direito à licença de exploração dos serviços de chamada de longa distância nacional ou internacional para as operadoras vencedoras da licitação relativa a qualquer área do SMP. Ante tais alterações, é possível inferir que, uma vez controlando operadoras de telefonia fixa que já disponibilizavam os serviços de longa distância nacional e internacional, qualquer grupo controlador que adquirisse uma licença do Serviço Móvel Pessoal se beneficiaria da exploração de três tipos de serviços em uma mesma região - o serviço de telefonia fixa local, o de longa distância e o serviço de telefonia móvel. Considerando os níveis de integração vertical apresentados por Porter (1980) "integração total, parcial e quase integração" e analisando as operadoras Vivo, Tim, Claro e Oi, sob tal perspectiva, observa-se que a TNL Participações, grupo que controlava a Telemar (operadora de telefonia fixa local e de longa distância) entrou no mercado de telefonia móvel criando uma operadora (Oi), que atua coincidentemente nas regiões em que a Telemar atuava. Em decorrência, a Oi e Telemar formalizaram o lançamento da marca única da operadora, em março de 2007, tornando-se uma mesma operadora e ofertando a telefonia 
fixa e móvel (Oi Fixo e Oi Móvel) além dos demais serviços de comunicação de dados disponibilizados pela Telemar, caracterizando um processo de integração total. As demais operadoras analisadas, Claro, Tim e Vivo, por apresentarem controladores que já detinham concomitantemente operadoras de telefonia fixa, porém com atividades não integradas operacionalmente entre elas e as primeiras, ${ }^{10}$ caracterizam quase integrações verticais entre elas e as operadoras de telefonia fixa. O quadro 2 resume as três alterações na estrutura do setor de telefonia móvel no Brasil em decorrência do SMP.

\section{Quadro 2}

Indicadores de alteração estrutural da indústria (Porter, 1980)

\begin{tabular}{|c|c|c|c|c|c|}
\hline \multirow[b]{2}{*}{$\begin{array}{l}\text { Operadoras } \\
\text { analisadas }\end{array}$} & \multirow[b]{2}{*}{$\begin{array}{c}\text { Grupo } \\
\text { controlador }\end{array}$} & \multicolumn{2}{|c|}{ Redução das barreiras de entrada } & \multirow{2}{*}{$\begin{array}{l}\text { Intensidade da } \\
\text { concorrência }\end{array}$} & \multirow{2}{*}{$\begin{array}{c}\text { Integração } \\
\text { vertical } \\
\text { Nível de } \\
\text { integração } \\
\text { vertical com a } \\
\text { operadora fixa }\end{array}$} \\
\hline & & $\begin{array}{c}\text { Grupo } \\
\text { controlador } \\
\text { atuava na } \\
\text { telefonia fixa }\end{array}$ & $\begin{array}{c}\text { Grupo } \\
\text { controlador } \\
\text { atuava na } \\
\text { telefonia móvel }\end{array}$ & & \\
\hline Vivo & $\begin{array}{l}\text { Telefônica } \\
\text { e Portugal } \\
\text { Telecom }\end{array}$ & $\begin{array}{l}\text { Sim (Telefônica } \\
\text { SP) }\end{array}$ & Sim (própria Vivo) & $\begin{array}{c}\text { Migração da } \\
\text { licença do SMC } \\
\text { para o SMP }\end{array}$ & $\begin{array}{c}\text { Quase } \\
\text { integração }\end{array}$ \\
\hline Tim & $\begin{array}{l}\text { Telecom } \\
\text { Itália }\end{array}$ & $\begin{array}{c}\text { Sim (Brasil } \\
\text { Telecom) e } \\
\text { TIM Celular } \\
\text { (operadora de } \\
\text { longa distância) }\end{array}$ & $\begin{array}{l}\text { Sim (Tim } \\
\text { Nordeste, Tim Sul } \\
\text { e Maxitel) }\end{array}$ & $\begin{array}{l}\text { Novo entrante } \\
\text { nas áreas em } \\
\text { que ainda não } \\
\text { atuava - } \\
\text { bandas A e B }\end{array}$ & $\begin{array}{c}\text { Quase } \\
\text { integração }\end{array}$ \\
\hline Claro & $\begin{array}{l}\text { América } \\
\text { Móvil }\end{array}$ & $\begin{array}{c}\text { Não, } \\
\text { posteriormente } \\
\text { adquiriu a } \\
\text { Embratel }\end{array}$ & $\begin{array}{c}\text { Não, } \\
\text { posteriormente } \\
\text { adquiriu } \\
\text { operadoras das } \\
\text { bandas A e B }\end{array}$ & $\begin{array}{c}\text { Adquiriu } \\
\text { empresas das } \\
\text { bandas A e B } \\
\text { Novo entrante } \\
\text { nas áreas em que } \\
\text { ainda não atuava }\end{array}$ & $\begin{array}{c}\text { Quase } \\
\text { integração }\end{array}$ \\
\hline Oi & $\begin{array}{c}\text { TNL } \\
\text { Participações }\end{array}$ & SIM (Telemar) & Não & Novo entrante & $\begin{array}{l}\text { Integração } \\
\text { total }\end{array}$ \\
\hline
\end{tabular}

\section{Estratégias competitivas das operadoras pós-SMP}

Segundo Porter (1980), diante de um processo evolutivo em uma indústria, sugere-se uma reavaliação do posicionamento estratégico das firmas que nela

\footnotetext{
${ }^{10}$ Segundo as informações obtidas pelas entrevistas realizadas.
} 
concorrem, a fim de que elas possam defender-se de novas configurações das forças ou influenciá-las em seu favor, por meio de uma das estratégias genéricas - liderança em custos, diferenciação ou enfoque. A fim de se identificar quais as estratégias adotadas pelas operadoras pós-SMP é preciso analisar a estrutura do setor durante o período, sintetizada no quadro 3.

$$
\text { Quadro } 3
$$

\section{Análise estrutural do setor de telefonia móvel após o SMP}

\begin{tabular}{|c|c|c|}
\hline Forças que atuam sobre a indústria & Intensidade & Características identificadas \\
\hline \multirow[t]{2}{*}{ Ameaça de novos entrantes } & \multirow[t]{2}{*}{ Baixa } & Barreiras de entrada elevadas \\
\hline & & Possibilidade de retaliação elevada \\
\hline \multirow[t]{3}{*}{ Rivalidade entre os concorrentes } & \multirow[t]{3}{*}{ Intensa } & Custos fixos elevados \\
\hline & & Concorrentes concentrados \\
\hline & & Diferenciação dos serviços baixa \\
\hline Ameaça de substituição & Moderada & $\begin{array}{l}\text { Produtos substitutos existentes, mas a ameaça } \\
\text { encontra-se limitada à aceitação das novas } \\
\text { tecnologias e ao aspecto regulatório }\end{array}$ \\
\hline \multirow{2}{*}{$\begin{array}{l}\text { Poder de negociação dos } \\
\text { compradores (usuários do serviço de } \\
\text { telefonia móvel) }\end{array}$} & \multirow[t]{2}{*}{ Moderada } & Os custos de mudança para o usuário existem \\
\hline & & Nível de informação sobre o produto moderada \\
\hline \multirow{3}{*}{$\begin{array}{l}\text { Poder de negociação dos } \\
\text { fornecedores de aparelhos e de } \\
\text { infraestrutura de rede }\end{array}$} & \multirow[t]{3}{*}{ Intensa } & Importância do insumo (aparelho) elevada \\
\hline & & $\begin{array}{l}\text { Concentração de fornecedores de aparelhos } \\
\text { reduzida }\end{array}$ \\
\hline & & $\begin{array}{l}\text { Importância do insumo (infraestrutura de rede) } \\
\text { elevada }\end{array}$ \\
\hline
\end{tabular}

A ameaça de novos entrantes demonstrou-se reduzida em função das elevadas barreiras de entrada e da possibilidade de retaliação pelos atuais concorrentes do setor. As elevadas barreiras de entrada explicam-se:

v pela necessidade de escala, caracterizada por uma peculiaridade do setor de telecomunicações — a economia de densidade (Armstrong, 1997:66) - menor custo per capita da instalação da tecnologia de rede em função da densidade populacional;

v pela necessidade de capital para aquisição das licenças de exploração do serviço (cujos valores arrecadados pela Anatel nas licitações do SMC e SMP ultrapassaram, segundo Dias, 2002, os R 20 bilhões, denotando um valor médio de $\mathrm{R} \$ 749,5$ milhões por licença adquirida), implantação da rede de comunicação, impactada pela extensão das áreas geográficas ampliadas pelo SMP (Resolução Anatel no 235/2000 e subsequentes), aquisição de no- 
vos clientes em face de uma taxa de penetração do serviço móvel de 53,61\% (Anatel, 2007c) e os subsídios nos aparelhos celulares como estímulo à adesão de novos clientes (Anuário Telecom, 2006).

Considerando-se os valores investidos nas licitações e o investimento em ativos de baixa liquidez (Armstrong, 1997), é possível inferir que as operadoras necessitam de recursos substanciais para financiar suas operações, daí emergindo um maior comprometimento e possíveis retaliações.

A rivalidade entre os concorrentes demonstrou-se intensa em função de altos custos demandados pela estrutura da rede de comunicação, independentemente do número de acessos que dela fazem uso (Ribeiro Filho e Correia, 1999); da concentração do mercado em que quatro operadoras respondem por 90\% da base de clientes (Anatel, 2007a); e da baixa diferenciação dos serviços (Curwen, 2006; Bloch-Morange e Fontela, 2003; OECD, 2005). Foi identificado que as operadoras analisadas atendem aos mesmos tipos de clientes (além de oferecer preços menores para chamadas de longa distância efetuadas com o Código de Seleção da operadora pertencente à operadora de telefonia fixa controlada pelo mesmo grupo, quando comparadas às operadoras independentes).

A ameaça de produtos substitutos existe, tanto com o WiMax ${ }^{11}$ (Resolução Anatel no 365/2004), ofertado pelas operadoras Embratel e Brasil Telecom, transmitindo, via IP, voz e dados em uma mesma rede sem fio, também observadas nas experiências internacionais da Inglaterra, Estados Unidos, Japão e Coréia (Curwen, 2006), quanto com o trunking, que tem como principal operadora a Nextel - serviço regulado a partir da Resolução da Anatel no 275 , de 16 de setembro de 2001, porém é preciso que haja uma aceitação pelo mercado de tais tecnologias (OECD, 2005:60). Por outro lado, a restrição regulatória limita a prestação do trunking somente a clientes corporativos, tornando a força de substituição de tais produtos limitada.

O poder de negociação dos compradores (usuários do serviço de telefonia móvel) foi considerado moderado em função dos custos de mudança para o cliente (Armstrong, 1997) decorrentes do custo de conexão, tal qual a necessidade de um aparelho celular específico ao padrão tecnológico da operadora

${ }^{11}$ WiMax é uma tecnologia sem fio, desenvolvida para oferecer acesso banda larga a distâncias típicas de 6 a $9 \mathrm{~km}$. A exemplo do que ocorre no celular, o WiMax é implantado em células. Da estação base é possível a transmissão para uma estação terminal que fornece acesso a uma rede local (WiFi, por exemplo) ou diretamente até os dispositivos dos usuários (Teleco, 2007b). 
— CDMA, TDMA ou GSM; da portabilidade numérica — a possibilidade de o cliente mudar de operadora, mantendo o mesmo número que utilizava; ${ }^{12}$ das externalidades em rede - em função das quais um usuário beneficia-se com a adesão de mais usuários à rede móvel, estes últimos amenizados por meio de determinações regulatórias; ${ }^{13}$ bem como do moderado nível de informação dos clientes sobre os produtos ofertados pelas operadoras, uma vez que a comparação das ofertas e preços institucionais das operadoras é plenamente possível - elas disponibilizam ao público informações sobre seus produtos e a composição dos seus pacotes de serviços e respectivos preços, seja por meio de suas lojas ou dos sites institucionais na internet, porém tal comparação é bastante complexa.

$\mathrm{O}$ poder de negociação dos fornecedores, sejam eles fornecedores de aparelhos ou de infraestrutura de rede, demonstrou-se intenso em função: da relevância dos aparelhos tanto para atrair o cliente de outra operadora, quanto para fidelizá-lo (Anuário Telecom, 2006), ainda que a concentração dos fornecedores de aparelhos no setor encontre-se menor durante o período analisado (SMP) do que anteriormente - a tecnologia GSM é um padrão tecnológico adotado por $80 \%$ da base de usuários no mundo (Teleco, 2007a), atraindo fornecedores de aparelhos, que atuavam no mercado internacional, para o mercado brasileiro (Anuário Telecom, 2004), reduzindo a concentração no setor e o poder de negociação dos fornecedores que aqui se encontravam, criando inclusive a possibilidade de importação de aparelhos pelas operadoras móveis. Como exemplos da expansão do número de fornecedores no mercado nacional, Motorola, Nokia, Siemens, Samsung, Sony, LG, HP e Pantech são citados nos relatórios anuais do setor (Anuário Telecom, 2003, 2004, 2005, 2006). Por fim, as relações tecnológicas quase verticais nesse setor (Fransman, 2001b), em que a tecnologia adotada pela operadora determinará quem serão seus fornecedores — associada à expansão da tecnologia GSM no país (Anuário

\footnotetext{
${ }^{12}$ Armstrong (1997:67): "Se os usuários tiverem que mudar seus números tipicamente enfrentarão custos financeiros como (...) possíveis perdas de clientes potenciais que não têm seu novo número".

${ }^{13}$ A observação a esse respeito é que a Anatel, por meio da Resolução no 460, de 10 de março de 2007, instaurou a portabilidade numérica, a partir de meados desse ano, tornando o número do celular independente da operadora do cliente. Por sua vez, as externalidades em rede, que também favoreceriam a permanência do cliente em uma operadora, são compensadas pela exigência de interoperabilidade das redes móveis de comunicação, condição imposta pela Anatel para qualquer entrante da indústria, como identificado no regulamento do SMP.
} 
Telecom, 2003, 2004, 2005, 2006) —, atribuem-se aos fornecedores da infraestrutura de rede um intenso poder de negociação.

A análise estrutural do setor de telefonia móvel, após o SMP, realizada sobre as origens das cinco forças competitivas, apresenta reduzida ameaça de novos entrantes, uma intensa rivalidade entre os concorrentes, a ameaça de produtos substitutos, um relativo poder de negociação dos compradores e um intenso poder de negociação dos fornecedores. Tais características indicam um mercado típico de commodities tanto anteriormente (Ribeiro Filho e Correia, 1999) quanto após o SMP e permitem inferir que há, nesse período, uma pressão maior sobre as margens das operadoras, sugerindo a opção das mesmas por uma estratégia de liderança em custos. No entanto, entre os serviços observados, foi identificado que todas as operadoras analisadas disponibilizam ofertas que compartilham minutos entre a telefonia móvel e a telefonia fixa de longa distância via CSP da operadora fixa do mesmo grupo. Paralelamente, verificou-se que uma das operadoras - a Oi — disponibiliza, além do benefício do CSP, pacotes de telefonia móvel com opções de assinatura de internet de banda larga e ligações locais gratuitas, desde que originadas pelo telefone fixo da própria operadora (antiga Telemar), diferenciando-se, no período da pesquisa, das demais operadoras analisadas - ainda que a Tim tenha lançado um plano semelhante, denominado Tim Casa, que inclui minutos para a realização de chamadas originadas do celular para telefones fixos a preços similares às tarifas cobradas pela telefonia fixa local. Posteriormente a tal produto (Oi Conta Total), a Oi disponibilizou, em abril de 2007, outro serviço em que um único aparelho celular, que apresente a funcionalidade de transmissão de dados sem fio do tipo bluetooth, torna possível a convergência da rede de telefonia fixa e móvel, permitindo ao usuário, por meio de seu aparelho celular, originar ou receber ligações da telefonia fixa ou móvel automaticamente (Oi Flex). Assim, tanto os serviços identificados nas ofertas das operadoras analisadas, que compartilham minutos entre a telefonia fixa e móvel, via CSP, quanto o que se utiliza de um único dispositivo (aparelho) para a convergência das redes fixa e móvel, encontram-se operando no que a literatura (Passmore, 2005; Curwen, 2006; Buckley, 2007) denomina convergência fixa-móvel (FMC).

A convergência fixa-móvel (FMC) é "uma integração transparente, para o usuário, de redes e serviços entre a telefonia fixa e móvel" (Curwen, 2006:2), categorizada em três níveis: o compartilhamento de atividades de back-office, forma mais simples de convergência na qual uma mesma companhia oferta serviços fixos e móveis, ainda que por setores diferentes em sua estrutura organizacional; o bundling, maneira mais comum, que consiste na oferta de minutos 
fixos e móveis em um mesmo pacote de serviços; e o nível mais representativo de convergência que é aquele em que um cliente, independentemente de sua localização, tanto origina quanto recebe chamadas fixas e móveis por meio de um único dispositivo (aparelho) - desde que a alternância entre os modos de comunicação fixa ou móvel ocorra de modo transparente ao usuário. Entre os fatores econômicos que estimularam a discussão do tema, ao final dos anos 1990, as operadoras de telefonia fixa e móvel perceberam ganhos de escala na busca de caminhos convergentes. Para as operadoras fixas, por sua vez, a convergência significava a redução da capacidade ociosa de sua rede com o aumento do tráfego de voz e de dados, já que a base de clientes móveis costuma ser maior que o total de clientes da rede de comunicação fixa. Para as operadoras móveis, a rede de comunicação fixa é um meio pelo qual as operadoras poderiam estar interligadas, reduzindo os custos de investimento e possibilitando-lhes fazer frente à ameaça de produtos substitutos como o WiMax e o VoIP ofertados pelas operadoras fixas. Em síntese, Curwen (2006:6) apresenta a convergência "como um meio para se superar a comoditização dos serviços de voz, reduzir os custos pelo compartilhamento de excessos de clientes ou de capacidade ociosa, melhorar a qualidade dos serviços e diferenciar-se dos demais competidores". Diante dessa afirmativa, e levando-se em conta os serviços ofertados pelas operadoras analisadas, concluiu-se que as operadoras Vivo, Tim, Claro e Oi apresentaram, a partir de 2006, a convergência fixa-móvel de nível intermediário (bundling). No entanto, como identificado durante as entrevistas, o nível de convergência apresentado pela operadora Oi diferenciou-se das demais operadoras, visto que ela também apresentou a convergência de back-office por meio da integração da sua estrutura organizacional com a antiga operadora fixa Telemar (operadora de telefonia fixa e de dados do mesmo grupo). A Oi oferece bundling de serviços fixos, móveis, de internet e de telefonia fixa: ${ }^{14}$ e lançou no mercado a convergência fixa-móvel de último nível. ${ }^{15}$

\section{Os mapas estratégicos do setor, após o SMP}

Com o SMP, o setor de telefonia móvel no Brasil transformou-se de um estágio transitório dualista (Santa Rita e Sbragia, 2004) para uma estrutura de mercado oligopolista, no qual as operadoras aqui analisadas - Vivo, Tim,

\footnotetext{
${ }^{14}$ Serviço denominado Oi Conta Total.

${ }^{15}$ Serviço denominado Oi Flex.
} 
Claro e Oi - respondem por mais de $90 \%$ da base total de clientes. A análise estrutural do setor e mesmo o comportamento público das operadoras têm sugerido a adoção inicial, por essas empresas, de uma estratégia genérica (Porter, 1980) de liderança de custos, seguida, no caso da Oi, de uma estratégia genérica de diferenciação, em face dos níveis de convergência identificados. Diferenças no posicionamento estratégico podem ser explicadas pela existência de grupos estratégicos, "um conjunto de firmas de uma indústria que estão seguindo uma estratégia idêntica ou semelhante, ao longo das dimensões de suas estratégias competitivas" (Porter, 1980:133). Recorrendo à construção de uma escala ordinal de medidas qualitativas (Pereira, 2001), o quadro 4 relaciona as dimensões estratégicas do setor de telefonia móvel com os valores representativos de suas intensidades, considerando-se: o nível de integração vertical (Porter, 1980) da operadora móvel com a operadora fixa controlada pelo mesmo grupo; o nível de convergência fixa-móvel (Curwen, 2006) identificado nas operadoras; e a especialização geográfica das operadoras, como definidas pela Anatel, na Resolução no 235/2000 do SMP.

Quadro 4

Dimensões estratégicas das operadoras analisadas

\begin{tabular}{|lcccc|}
\hline Dimensões estratégicas & 1 & 2 & 3 & 4 \\
\cline { 2 - 5 } & Sem integração & Quase integração & Integração total & - \\
\hline $\begin{array}{l}\text { Nível de integração vertical } \\
\text { com a operadora fixa }\end{array}$ & Sem convergência & Back-office & Bundle & Único \\
$\begin{array}{l}\text { Nível de convergência } \\
\text { (FMC) }\end{array}$ & dispositivo \\
Especialização geográfica* & $\begin{array}{c}\text { Atua apenas em uma } \\
\text { região do SMP }\end{array}$ & $\begin{array}{c}\text { Atua em duas } \\
\text { regiões do SMP }\end{array}$ & $\begin{array}{c}\text { Atua em três } \\
\text { regiões do SMP }\end{array}$ & - \\
\hline
\end{tabular}

* Esta dimensão representa a região geográfica atendida pela operadora móvel, ressaltando-se que, com o SMP, o território nacional foi dividido em três regiões: Região I, Região II e Região III.

Seguindo o modelo gráfico apresentado por Porter (1980:134), para os mapas estratégicos de uma indústria é possível construir dois mapas estratégicos do setor de telefonia móvel que representem a intensidade das dimensões estratégicas das operadoras sintetizadas no quadro 4. Observa-se que a terceira dimensão estratégica utilizada nos mapas (especialização geográfica) é representada pelo tamanho das circunferências que caracterizam as operadoras móveis em análise. 
Figura 1

Mapa estratégico das operadoras móveis antes da convergência fixo-móvel

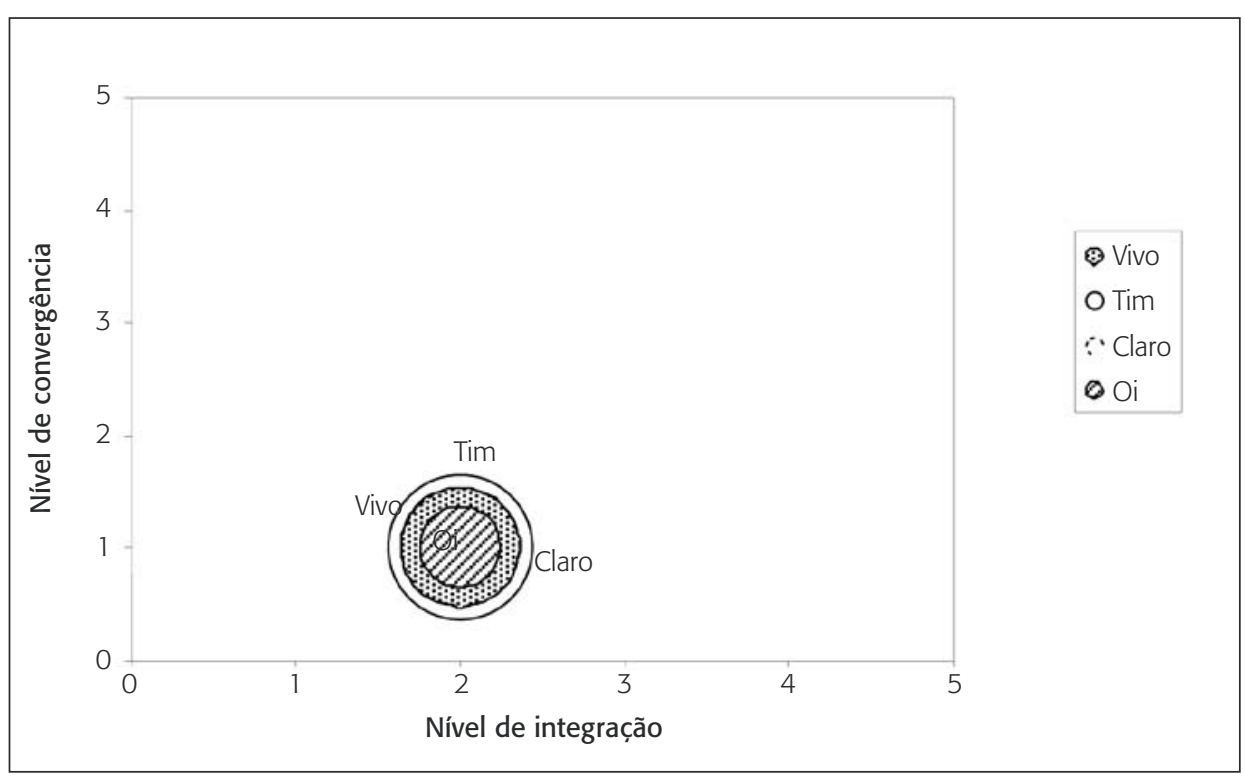

Figura 2

Mapa estratégico das operadoras móveis após a convergência fixo-móvel

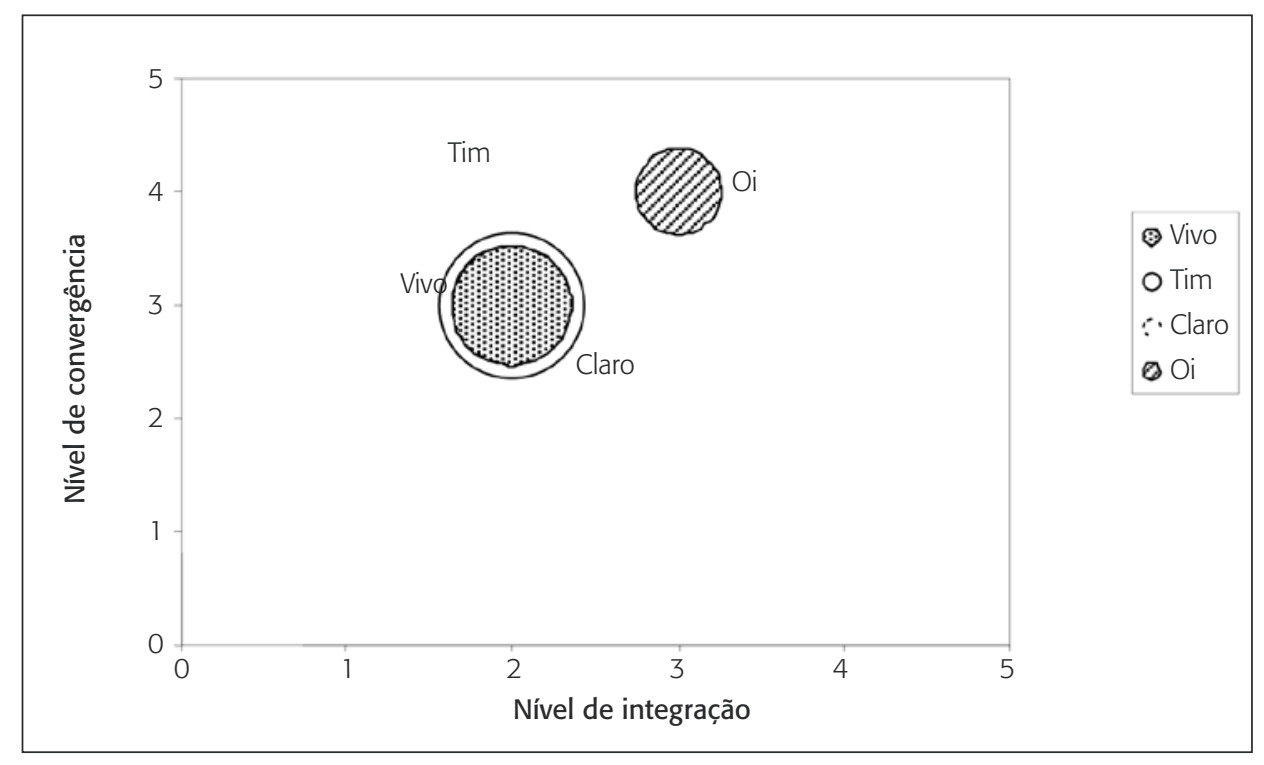

RAP - RIO DE JANEIRO 43(1):123-50, JAN./FEV. 2009 
No primeiro momento, após o SMP, as operadoras analisadas apresentavam um posicionamento estratégico semelhante, que se diferenciava unicamente pela área de cobertura das operadoras. A Tim adotava uma posição de cobertura nacional, enquanto a Vivo e a Claro encontravam-se no mesmo escopo de cobertura e a Oi optava por uma região de cobertura menor (idêntica à área da Telemar). De uma maneira geral as operadoras móveis apresentavam quase integrações com as operadoras fixas, sem que isso se traduzisse, explicitamente, em serviços convergentes (figura 1). No segundo momento, a partir de 2006, os posicionamentos estratégicos das operadoras alteraramse nas dimensões da convergência e da integração enquanto mantiveram as estratégias de cobertura. A Tim, a Vivo e a Claro posicionaram-se em um nível de convergência do tipo bundle, com o mesmo nível de quase integração anterior, já a Oi optou por uma estrutura integrada com a operadora fixa (antiga Telemar), ofertando simultaneamente produtos convergentes como bundle e convergência da sua rede de telefonia fixa e móvel (figura 2).

\section{Conclusões}

É possível concluir que o Serviço Móvel Pessoal, por meio do seu regulamento e do plano geral de autorizações, promoveu significativas alterações no arcabouço regulatório do setor de telefonia móvel comparativamente ao contexto anterior. Entre essas alterações destacam-se: a formalização da licença do tipo autorização; a tecnologia GSM; a permissão para que controladores de operações na telefonia fixa ou móvel participassem do processo de licitação do SMP; a redefinição das áreas geográficas de prestação desse serviço de modo semelhante à telefonia fixa; a possibilidade da seleção, pelo usuário, da prestadora de ligações do tipo longa distância; e o direito das operadoras vencedoras do SMP à exploração do serviço de longa distância nacional e internacional.

Tais alterações podem ser consideradas parte de um processo evolutivo dessa indústria, oriundo das mudanças na política governamental que a regulamentam, alterando as fontes das forças competitivas que sobre ela atuam. Essas alterações nas forças competitivas reduziram, naquele período, suas barreiras de entrada, permitindo a inserção de novas operadoras das bandas D e E do SMP, oriundas da telefonia fixa ou móvel, intensificando a concorrência no setor e estabelecendo integrações verticais entre operadoras de telefonia móvel e operadoras da telefonia fixa. Este conjunto se conforma como o resultado final de uma clara política da Anatel para promoção da concorrência na telefonia fixa por meio das operadoras da telefonia móvel. 
Vale ressaltar que essas alterações no setor da telefonia móvel brasileira alinham-se com as evoluções estruturais identificadas por outros autores como Pires (1999) e Fransman (2001b), no setor de telecomunicações dos Estados Unidos, Japão, França, Itália e Inglaterra, também em decorrência das políticas de suas agências reguladoras aparentemente em busca de uma estrutura de mercado mais competitiva. É possível concluir que, a exemplo do que ocorreu naqueles países, tal processo engendrou uma alteração na estrutura do mercado caracterizada em dois níveis - nacional (macro) e regional (micro).

Em uma análise macro, foi observada a concentração do mercado nacional em torno de quatro operadoras - Vivo, Tim, Claro e Oi - , propiciando a essas organizações responder por mais de $90 \%$ da base de clientes móveis no país. Em uma análise micro, o que se observou em nível regional, cujos mercados apresentavam-se sob regimes de duopólio, foi a escalada nos níveis médios de competitividade da telefonia móvel com a inserção das novas operadoras oriundas do SMP e seus serviços ofertados à população local.

As alterações regulatórias foram capazes de impactar a estrutura do mercado, determinando, após o SMP, uma diminuição da ameaça de novos entrantes, a manutenção da ameaça de substituição de seus produtos, a manutenção do moderado poder de negociação dos usuários e simultaneamente a diminuição do poder dos fornecedores de aparelhos e das redes de comunicação. Esse novo quadro, ainda que bastante propício às operadoras, levou as operadoras analisadas a manterem-se fiéis às práticas coerentes com a estratégia genérica de liderança em custos, mesmo diante de relações de quase integração entre essas e as operadoras de telefonia fixa do mesmo grupo.

A mudança nos comportamentos estratégicos das operadoras observadas se dá, inicialmente, com a identificação de ofertas de serviços convergentes do tipo bundle pelas operadoras Vivo, Tim, Claro e Oi, seguidas de um processo de integração total entre a operadora Oi e a antiga Telemar, ofertando, por conseguinte, serviços convergentes por meio de dispositivos únicos pela operadora Oi. Este último resultado levou à adoção do que o clássico referencial de Michael Porter classifica como uma estratégia genérica de diferenciação.

Não foi possível responder aqui se o nível de integração vertical entre as operadoras analisadas e as operadoras de telefonia fixa do mesmo grupo constitui condição necessária para a oferta de serviços convergentes ao mercado. Mas é possível observar que, tanto a oferta de serviços convergentes do tipo bundle, quanto a de serviços convergentes, por meio de dispositivos únicos, foram precedidas respectivamente de integrações parciais e totais entre operadoras fixas e móveis. 
A fim de representar graficamente o posicionamento estratégico das operadoras analisadas no cenário nacional, recorreu-se à construção dos mapas estratégicos (Porter, 1980) que representam os conjuntos dessas operadoras dispostas em grupos conforme suas estratégias adotadas, sendo possível perceber a evolução do posicionamento competitivo dessas operadoras em dois momentos, antes e após a convergência fixa-móvel (FMC), com a formação de grupos estratégicos que se destacam, além do nível de convergência, em função do nível de integração vertical com operadoras de telefonia fixa e das áreas de prestação do serviço no território nacional.

Finalmente, é possível concluir que o referencial teórico clássico de estratégia competitiva (Porter, 1980, 1985) aqui utilizado na identificação das estratégias individuais e em grupo das operadoras móveis, apesar de ser tão clássico e tão criticado, é eficaz para uma análise contextual e abrangente, em nível setorial. Tal eficácia, talvez seja ainda mais relevante se a indústria em pauta apresenta forte influência do governo na definição das normas que a regem (como foi o caso aqui analisado). No entanto, a predominância de aspectos tecnológicos no setor de telecomunicações requer uma análise complementada por um referencial teórico especializado (Armstrong, 1997; Gaffard e Krafft, 2000; Fransman, 2001a; Curwen, 2006) capaz de subsidiar a compreensão das ações das firmas que nela se encontram.

\section{Considerações finais}

Este artigo analisa as operadoras de telefonia móvel e seu setor a partir do SMP até meados de 2007. Em função de seu recorte temporal, após o encerramento deste artigo, novos fatos foram observados entre as operadoras analisadas como: a oferta de serviços convergentes de último nível pela operadora Tim; novas regras editadas pela Anatel sobre a terceira geração da telefonia móvel (3G) no Brasil, significando novas licenças, tecnologia e serviços inovadores; a fusão das operadoras Oi e Brasil Telecom, ainda sob parecer da Anatel quando foi finalizado este artigo; a expansão da área de atuação das operadoras Vivo e Oi, seja por aquisição de operadoras já existentes em áreas que ainda não atuavam ou por iniciar novas operações, entre outros fatos, que justificam a continuação deste trabalho, incorporando as movimentações estratégicas das operadoras aqui estudadas após esse primeiro período de análise, e também os resultados obtidos com a utilização da convergência fixa móvel como fonte de vantagem competitiva para as operadoras que a adotaram. 


\section{Referências bibliográficas}

AAKER, D. A. Managing assets and skills: the key to a sustainable competitive advantage. California Management Review, California, v. 31, n. 2, p. 91-106, Winter 1989.

ANATEL. Operadoras do serviço móvel pessoal. Brasília, 2005. Disponível em: <www. anatel.gov.br/Tools/frame.asp?link=/comunicacao_movel/smc/smc_smp_novo_cenario.pdf>. Acesso em: 18 out. 2005.

. Página istitucional - Serviços. Brasília, 2006a. Disponível em: <www. anatel.gov.br>. Acesso em: 23 fev. 2007.

. Apresentação institucional - Telecom no Brasil e Anatel. Brasília, 2006b. Disponível em: <www.anatel.gov.br/Tools/frame.asp?link=/acontece_anatel/ palestras/conselhodiretor/palestra_jl_telecom_brasil180506.pdf $>$. Acesso em: 23 fev. 2007.

. Crescimento das comunicações móveis (1990-2007). Brasília, 2007a. Disponível em:<http://sistemas.anatel.gov.br/smp/administracao/consulta/ acompanhamento estacoes $/$ tela.asp?CodTopico $=2440 \&$ CodArea $=31 \&$ CodTemplate =413\&CodMenuServico=43>. Acesso em: 23 jan. 2007.

. Conheça a Anatel. Brasília, 2007b. Disponível em: <www.anatel.gov.br/in$\overline{\text { dex.asp }}$ ?link =/conheca_anatel/apresentacao/apresenta1.htm?Cod $=11>$. Acesso em: 10 jan. 2007.

. Superada marca de 100 milhões de celulares em operação. Brasília, 2007c. Disponível em: <www.anatel.gov.br/Tools/frame.asp?link=/biblioteca/ releases/2007/release_16_02_2007mm.pdf>. Acesso em: 17 fev. 2007.

. Licitação banda A - empresas participantes x valores oferecidos. Brasília, 2007d. Disponível em: <www.anatel.gov.br/Tools/frame.asp?link=/comunicacao movel/smc/outrosdocs/licitacao_banda_a_participantes_valores.pdf $>$. Acesso em: 17 fev. 2007.

. Prestadoras do serviço móvel pessoal. Brasília, 2007e. Disponível em: <http://sistemas.anatel.gov.br/stel/consultas/ListaPrestadorasServico/tela. asp?pNumServico=010>. Acesso em: 17 fev. 2007.

. Biblioteca. Brasília, 2007 f. Disponível em: <www.anatel.gov.br/biblioteca/

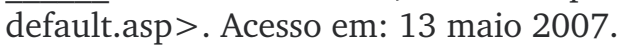

. Dados relevantes. Brasília, 2007g. Disponível em: <www.anatel.gov.br/Tools/ frame.asp?link=/comunicacao_movel/smc/dados_relevantes_smc_smp.pdf $>$. Acesso em: 15 maio 2007.

. Planos de serviços. Brasília, 2007h. Disponível em: <www.anatel.gov.

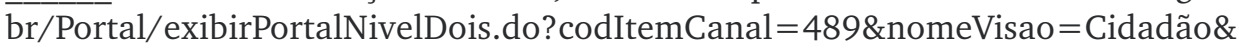


nomeCanal $=$ Telefonia\%20Móvel\&nomeItemCanal $=$ Planos\%20de\%20Serviços $>$. Acesso em: 15 maio 2007.

. Dados de acessos móveis em operação e densidade, por unidade da Federação, do serviço móvel pessoal. Brasília, 2008. Disponível em: <www.anatel.gov.br/Portal/ documentos/209575.pdf>. Acesso em: 15 mar. 2008.

ANUÁRIO TELECOM. São Paulo: Plano Editorial Ltda., 2001.

. São Paulo: Plano Editorial Ltda., 2002.

. São Paulo: Plano Editorial Ltda., 2003.

. São Paulo: Plano Editorial Ltda., 2004.

. São Paulo: Plano Editorial Ltda., 2005.

. São Paulo: Plano Editorial Ltda., 2006.

ARMSTRONG, M. Competition in telecommunications. Oxford Review of Economic Policy, Oxford, v. 13, n. 1, p. 64-82, Spring 1997.

BARNEY, J. B. Organizational culture: can it be a source of sustained competitive advantage? Academy of Management Review, New York, v. 11, n. 3, p. 656-685, July 1986.

. Firm resources and sustained competitive advantage. Journal of Management, Bloomington, v. 17, n. 1, Mar. 1991.

BLOCH-MORANGE, G.; FONTELA, E. Mobile communication from voice to data: a morphological analysis. The Journal of Policy, Regulation and Strategy for Telecommunications, v. 5, n. 2, p. 24-33, 2003.

BNDES (Banco Nacional de Desenvolvimento Econômico e Social). Operadoras de telefonia móvel no Brasil. Cadernos de Infra-Estrutura. Rio de Janeiro, n. 19, jul. 2001.

BUCKLEY, S. Paths to convergence. Telecommunications International, v. 41, n. 2, Feb. 2007.

CAVALCANTE, A. B. O processo de privatização do setor de telecomunicações brasileiro: novas linhas de atuação. In: ENCONTRO ANUAL DA ASSOCIAÇÃO NACIONAL DOS PROGRAMAS DE PÓS-GRADUAÇÃO EM ADMINISTRAÇÃO, 23., 1999, Salvador. Anais... Foz do Iguaçu: Enanpad, 1999.

COOL, K.; SCHENDEL, D. Performance differences among strategic group members. Strategic Management Journal, Chichester, v. 9, n. 3, p. 207-223, May/June 1988.

CURWEN, P. Fixed-mobile convergence. Info: the Journal of Policy, Regulation and Strategy for Telecommunications, Information and Media, Bradford, v. 8, n. 3, p. 3-11, 2006. 
DESS, G. G.; DAVIS, P. S. Porter's (1980) generic strategies as determinants of strategic group membership and organizational performance. Academy of Management Journal, New York, v. 27, n. 3, p. 467-488, Sept. 1984.

DIAS, Lia Ribeiro (Coord.). A revolução da mobilidade: o celular no Brasil de símbolo de status a instrumento de cidadania. São Paulo: Plano Editorial, 2002.

DRANOVE, D.; PETERAF, M.; SHANLEY, M. Do strategic groups exist? An economic framework for analysis. Strategic Management Journal, Chichester, v. 19, n. 11, p. 1029-1044, Nov. 1998.

FOSS, N. J. Research in strategy, economics and Michael Porter. Journal of Management Studies, Oxford, v. 33, n. 1, p. 1-24, Jan. 1996.

; KNUDSEN, T. The resource-based tangle: towards a sustainable explanation of competitive advantage. Managerial and Decision Economics, Chichester, v. 24, n. 4, p. 291-307, June 2003.

FRANSMAN, M. Evolution of the telecommunications industry into the internet age. In: The international handbook on telecommunications economics. Aldershot: Edward Elgar, 2001a.

. Analysing the evolution of industry: the relevance of the telecommunications industry. Economics of Innovation \& New Technology, v. 10, n. 2/3, p. 109-140, Apr. 2001b.

. The telecoms boom and bust 1996-2003 and the role of financial markets. Journal of Evolutionary Economics, Netherlands, v. 14, n. 4, p. 369-406, 2004.

FREITAS, F. H. A regulação das telecomunicações no Brasil. 2000. Tese (Doutorado em Administração) - Escola de Administração da Universidade Federal da Bahia.

GAFFARD, J.; KRAFFT, J. Telecommunications: understanding the dynamics of the organization of the industry. Telecom Visions, Oct. 2000. Disponível em: <www. telecomvisions.com/articles/pdf/jackie.pdf>. Acesso em: 13 maio 2006.

GUILHOTO, L. F. M.; RUBAL, J. M. Estratégia de lançamento de novos produtos e de serviços inovadores em operadoras do sistema de telefonia fixo comutado (STFC). In: SBRAGIA, Roberto; GALINA, Simone V. R. (Eds.). Gestão da inovação no setor de telecomunicações. São Paulo: PGT/USP, 2004. p.193-230.

HANSEN, G. S.; WERNERFELT, B. Determinants of firm performance: the relative importance of economic and organizational factors. Strategic Management Journal, Chichester, v. 10, n. 5, p. 399-411, Sept./Oct. 1989.

HATTEN, K. J.; HATTEN, M. L. Strategical groups asymmetrical mobility barriers and contestability. Strategic Management Journal, Chichester, v. 8, n. 4, p. 329-342, July/Sept. 1987. 
ITU (International Telecommunication Union). Genebra, 2005. Disponível em: $<$ www.itu.int/ITU-D/ict/statistics/at_glance/cellular04.pdf >. Acesso em: 8 nov. 2005.

LAKATOS, Eva Maria; MARCONI, Marina de Andrade. Fundamentos de metodologia científica. 3. ed. São Paulo: Atlas, 1991.

MARTINS, G. A. Estudo de caso: uma estratégia de pesquisa. São Paulo: Atlas, 2006.

MASCARENHAS, B.; AAKER, D. Mobility barriers and strategic groups. Strategic Management Journal, Chichester, v. 10, n. 5, p. 475-485, Sept./Oct. 1989.

McGEE, J.; THOMAS, H. Strategic groups: theory, research and taxonomy. Strategic Management Journal, Chichester, v. 7, n. 2, p. 141-160, Mar./Apr. 1986.

MILLER, D. Relating Porter's business strategy to environment and structure: analysis and performance implications. Academy of Management Journal, Philadelphia, v. 31, n. 2, p. 280-308, June 1988.

MINTZBERG, H. The strategy concept I: five P's for strategy. California Management Review, Berkeley, v. 30, n. 1, p. 11-24, Fall 1987.

; AHLSTRAND, B.; LAMPEL, J. Safári de estratégia: um roteiro pela selva do planejamento estratégico. Tradução de Rivaldo Montingelli Jr. Revisão técnica de Carlos Alberto Vargas Rossi. Porto Alegre: Bookman, 2000.

NEVES, M. S. O setor de telecomunicações. In: SÃO PAULO, Elizabeth Maria de; KALACHE FILHO, Jorge (Orgs.). BNDES 50 anos — histórias setoriais. São Paulo: DBA Artes Gráficas, 2002. v. 1, p. 297-319.

NOVAES, Ana. Privatização do setor de telecomunicações no Brasil. In: PINHEIRO, A. C.; FUKASAKU, K. (Eds.). Privatização no Brasil: o caso dos serviços de utilidade pública. Rio de Janeiro: BNDES, 2000. cap. 5, p.145-178.

OECD. Digital broadband content: mobile content for new platforms. OECD, May 2005.

PASSMORE, D. A framework for fixed/mobile convergence. Business Communications Review. v. 35, n. 11, p. 12-13, Nov. 2005.

PATTON, Michael Quinn. Qualitative research and evaluation methods. 3. ed. Thousand Oaks: Sage Publications, 2002.

PEREIRA, Mirella Magalhães; GUEDES, L. G. R. Perspectivas das comunicações móveis no Brasil. Revista Digital Online, Brasília, v. 2, n. 1, p. 25-41, jan. 2004.

PETERAF, M. A. The cornerstones of competitive advantage: a resource-based. Strategic Management Journal, Chichester, v. 14, n. 3, p. 179-191, Mar. 1993.

; BARNEY, J. B. Unraveling the resource-based tangle. Managerial and Decision Economics, Chichester, v. 24, n. 4, p. 309-323, June 2003. 
PIRES, J. C. L. Reestruturação competitiva e regulação nos setores de energia elétrica e de telecomunicações. 1999. 272 f. Tese (Doutorado em Ciências Econômicas) - Instituto de Economia, Universidade Federal do Rio de Janeiro.

PORTER, M. How competitive forces shape strategy. Harvard Business Review, Boston, v. 57, p. 137-156, Nov. 1979.

. Competitive strategy. New York: Free Press, 1980.

. The contributions of industrial organization to strategic management. Academy of Management Review, New York, v. 6, n. 4, p. 609-620, Oct. 1981.

. Competitive advantage: creating and sustaining a superior performance. New York: Free Press, 1985.

. From competitive advantage to corporate strategy. Harvard Business Review, Boston, v. 65, n. 3, p. 43-59, May/June 1987.

. Towards a dynamic theory of strategy. Strategic Management Journal, Chichester, v. 12, p. 95-117, Winter 1991. Special issue. Nov. 1996.

What is strategy ? Harvard Business Review, Boston, v. 74, n. 6, p. 61-78,

RIBEIRO FILHO, A. P.; CORREIA, F. A. A. R. Comparação estratégica das forças que dirigem a concorrência nas indústrias de energia elétrica e telecomunicações no Brasil. In: ENCONTRO ANUAL DA ASSOCIAÇÃ̃O NACIONAL DOS PROGRAMAS DE PÓS-GRADUAÇÃO EM ADMINISTRAÇÃO, 23., 1999, Salvador. Anais... Foz do Iguaçu: Enanpad, 1999.

RICHARDSON, R. J. et al. Pesquisa social: métodos e técnicas. São Paulo: Atlas, 1999.

ROUSE, M. J.; DAELLENBACH, U. S. Rethinking research methods for the resourcebased perspective: isolating sources of sustainable competitive advantage. Strategic Management Journal, Chichester, v. 20, n. 5, p. 487-494, May 1999.

RUMELT, R. P. How much does industry matter? Strategic Management Journal, Chichester, v. 12, n. 3, p. 167-185, Mar. 1991.

SALGADO, L. H.; MOTA, R. S. (Eds.). Marcos regulatórios no Brasil: o que foi feito e o que falta fazer. Rio de Janeiro: Ipea, 2005.

SANTA RITA, Luciana; SBRAGIA, Roberto. Inovação em serviços no setor de telefonia móvel: uma análise sob a dimensão da competitividade. In: SBRAGIA, Roberto; GALINA, Simone V. R. (Eds.). Gestão da inovação no setor de telecomunicações. São Paulo: PGT/USP, 2004. cap. 9, p. 299-331.

SBRAGIA, Roberto et al. Panorama do setor de telecomunicações. In: SBRAGIA, Robert; GALINA, Simone V. R. (Eds.). Gestão da inovação no setor de telecomunicações. São Paulo: PGT/USP, 2004. cap. 1, p. 3-38. 
SCHMALENSEE, R. Do markets differ much? American Economic Review, Nashville, v. 75, n. 3, p. 341-351, 1985.

TEECE, D. J.; PISANO, G.; SHUEN, A. Dinamic capabilities and strategic management. Strategic Management Journal, Chichester, v. 18, n. 17, p. 509-533, Aug. 1997.

TELECO. Desempenho do setor de telecomunicações no Brasil: séries temporais. São Paulo: Telebrasil e Teleco, 2006.

. Celular por tecnologia. São Paulo, 2007a. Disponível em: <www.teleco. com.br/pais/celular.asp >. Acesso em: 13 maio 2007.

. WiMax tecnologia. São Paulo, 2007b. Disponível em: <www.teleco.com. br/wimax_tecnologia.asp >. Acesso em: 13 maio 2007.

VALENTE, Antonio C. Evolução do mercado de telecomunicações no Brasil no período pós-privatização. In: PINHEIRO, A. C.; FUKASAKU, K. (Eds.). Privatização no Brasil: o caso dos serviços de utilidade pública. Rio de Janeiro: BNDES, 2000. cap. 12, p. 355-362.

VENKATRAMAN, N.; PRESCOTT, J. E. Environment-strategy coalignment: an empirical test of its performance implications. Strategic Management Journal, New Jersey, v. 11, n. 1, p. 1-23, Jan. 1990a.

; ____. The market share-profitability relationship: testing temporal stability across business cycles. Journal of Management, Bloomington, v. 16, n. 4, p. 783-805, Dec. 1990b.

VERGARA, Sylvia Constant. Métodos de pesquisa em administração. São Paulo: Atlas, 2005.

WERNERFELT, B. A resource-based view of the firm. Strategic Management Journal, Chichester, v. 5, n. 2, p. 171-180, Apr./Jun. 1984.

YIN, Robert K. Case study research: design and methods. 3. ed. Thousand Oaks: Sage Publications, 2003. 